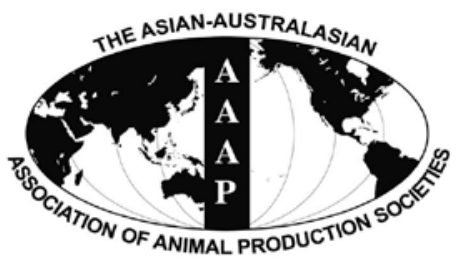

Asian-Aust. J. Anim. Sci.

Vol. 25, No. 1 : 52 - 58

January 2012

www.ajas.info

http://dx.doi.org/10.5713/ajas.2011.11167

\title{
Ovarian Response to Different Dose Levels of Follicle Stimulating Hormone (FSH) in Different Genotypes of Bangladeshi Cattle
}

\author{
M. S. Ali, M. A. M. Y. Khandoker, M. A. Afroz and A. K. F. H. Bhuiyan* \\ Department of Animal Breeding and Genetics, Bangladesh Agricultural University, Mymensingh, Bangladesh
}

\begin{abstract}
The experiment was conducted under the Department of Animal Breeding and Genetics, Bangladesh Agricultural University (BAU), Mymensingh from June, 2001 to December, 2005 in two different locations (Central Cattle Breeding and Dairy Farm and Bangladesh Livestock Research Institute in Savar, Dhaka) to observe ovarian response to different doses of FSH in three different genotypes of cattle- indigenous Local, Pabna cattle and Friesian $\times$ Local cross. Five different dose levels used were 200, 240, 280, 320 and $360 \mathrm{mg}$. Ovarian response as corpus luteum (CL), recovered embryo (RE) and of transferable embryos (TE) count in Local were significant for 320, 280 and 280 mg respectively. In Pabna cattle CL, RE and TE count were found significant for 360, 320 and 320 mg respectively. In Friesian×Local cross CL, RE and TE count were found significant for 360, 320 and 320 mg respectively. The excellent quality embryos showed significantly the highest yield (1.80 \pm 0.20$)$ in the 240 and $280 \mathrm{mg}$ FSH levels in Local genotype. In Pabna cattle, the highest yield (2.00 \pm 0.32$)$ was found at FSH level $320 \mathrm{mg}$. In Friesian $\times$ Local, the highest yield (2.20 \pm 0.20$)$ was found at FSH level 280 mg. (Key Words : Follicle Stimulating Hormone (FSH), Corpus Luteum, Recovered Embryo, Transferable Embryo)
\end{abstract}

\section{INTRODUCTION}

Bangladesh is a rich country in respect of cattle population of 22.97 million heads (DLS, 2009). Over $90 \%$ of the cattle population is indigenous zebu type and their productivity is very low in terms of milk or meat production. The native cattle are not described yet but some of them are considered potential in some Locality and are identified by its local name, such as Pabna cattle, Red Chittagong cattle, Munshiganj cattle, North Bengal Grey cattle and Nondescript Deshi or Local cattle (Bhuiyan et al., 2007). Importation of foreign germplasm started around 1930 in Bangladesh by bringing Hariana breed and it is still going on (Faruque and Bhuiyan, 2001). But genetic improvement programs of cattle have made little progress. For last 40 years only artificial insemination is used. Crossbreeding and grading up are the important tools in use. However, a new option is being used in different countries in the magnitude of genetic improvement of cattle that is Multiple Ovulation and Embryo Transfer (MOET). It is now feasible

\footnotetext{
* Corresponding Author: A. K. F. H. Bhuiyan. Tel: +880-9167401-6, Fax: +880-91-61510, E-mail: bhuiyanbau@gmail.com Received June 3, 2011; Accepted October 17, 2011
}

and is being widely exploited, both for its commercial and genetic advantages. Since middle of 1980s, MOET technology, for reproduction and genetic improvement of farm animals has been used in most of the developed and many of the developing countries around the world. In embryo transfer technology, there have been few improvements in the superovulation of cattle over past 25 years. In spite of the fact that embryo production per donor has not improved, there have been increases in embryo production per donor on a per unit time basis (Hasler, 2003). Donors are now repeatedly super ovulated for a period of 12 years, every 40 days or less with very satisfactory results (Hasler, 2003). Superovulation now can be initiated following insertion of a progesterone releasing device at any time of estrous cycles. Though a number of similar experiments have been carried out using western and Japanese breeds but ovarian response to different dose levels of follicle stimulating hormone (FSH) in different genotypes of cattle available in Bangladesh are absent. This study will therefore help to generate new data in the area of induction of ovulation in locally available cattle genotypes. These in turn will help to develop strategy for cattle improvement in Bangladesh using female reproductive biotechnological interventions such as multiple ovulation 
and embryo transfer (MOET). As embryo transfer technique is still new in Bangladesh, we need a clear understanding of superovulation technique and impact on different genotypes available in the country. In respect of this view, effect of Follicle Stimulating Hormone (FSH) was observed on three cattle genotypes of this country.

\section{MATERIALS AND METHODS}

\section{Location of the experiment}

The experiment was conducted under the Department of Animal Breeding and Genetics, Bangladesh Agricultural University (BAU), Mymensingh, Bangladesh from June 2001 to December 2005. Two different locations were used to make available the required genetic groups of experimental animals. The locations were: Central Cattle Breeding and Dairy Farm, Savar, Dhaka and Bangladesh Livestock Research Institute (BLRI), Savar, Dhaka.

\section{Selection and management of donor cows}

A total of 60 cows of three different genetic groups with 20 in each of the Local (Non-descript), Pabna $(\mathrm{Pb})$ and Friesian $\times$ Local $(F \times L)$ groups were used in this study as experimental donors. The selection was made based on good health along with reproductive superiority with at least twice normal cycling of behavioral estrous. The average age of donors of different genetic groups ranged from 4.0 to 6.0 years and that of body weight ranged from 260 to $420 \mathrm{~kg}$ for Local and Pabna genetic groups and that of Local×Friesian genetic group from 350 to $530 \mathrm{~kg}$ respectively.

The experimental donors were kept in cowsheds of Central Cattle Breeding and Dairy Farm, Savar, Dhaka and BLRI under existing care and management conditions in stanchion barn where the animals were fed two times in a day at 7 am and $3 \mathrm{pm}$ along with plenty of fresh drinking water. No extra care and management facilities were provided to the experimental animals during the experimental period to minimize the management effects on experimental results.

\section{Selection and management of recipient cows/heifers}

A total of 108 recipient cows/heifers were used in this experiment. The selection and management procedure of recipients were similar to those of donor cows. Moreover, the recipients were selected irrespective of genotype having good health and known reproductive history.

\section{Estrous synchronization of recipients to donor}

Estrous synchronization of 58 recipients to donor using Prostaglandin $F_{2 \alpha}$ analogue was done with a $2.0 \mathrm{ml}$ leuteolytic dose of Prostaglandin $\mathrm{F}_{2 \alpha}$ analogue (Prosolvin ${ }^{\circledR}$ Luprostiol $7.5 \mathrm{mg} / \mathrm{ml}$ ) injection to each of the recipient intramascularly upon confirmation of functional corpus luteum (CL) on either of the two ovaries by rectal palpation prior to $24 \mathrm{~h}$ of Prostaglandin $\mathrm{F}_{2 \alpha}$ analogue (Prosolvin ${ }^{\circledR}$ Luprostiol $7.5 \mathrm{mg} / \mathrm{ml}$ ) administration to the donor. For natural synchronization, 50 recipients estrous to donor estrous was confirmed by close observation in 3-4 occasions a day on available dry cows and heifers at the station during the estrous period of the superovulatory donor with a range of $\pm 24 \mathrm{~h}$. Further, the natural estrous of recipients was confirmed by consulting the heat detection and reproduction registers of the station for each of the individual recipients exhibited estrous.

\section{Superovulation with follicle stimulating hormone (FSH)}

Superovulation with follicle stimulating hormone (FSH) was carried out using 5 (five) different dose levels to each of the 3 (three) different genetic groups with 20 donors in each group to study the optimum ovarian response in respective genetic groups. The 5 different dose levels were: i) $200 \mathrm{mg}$ ii) $240 \mathrm{mg}$ iii) $280 \mathrm{mg}$ iv) $320 \mathrm{mg}$ and v) $360 \mathrm{mg}$ of FSH (FOLLTROPIN ${ }^{\circledR}-\mathrm{V}$ ) respectively. The total dose of FSH was divided into 4 (four) equal parts based on constant dosage level throughout the administration period according to Elsden et al. (1978). Each of the 4 parts of FSH was again sub-divided into 2 equal parts comprising a total of 8 equal parts of total FSH dosage. The 8 equal parts of divided FSH doses were administered to the donor in 4 consecutive days using each 2 parts in one day in two occasions $12 \mathrm{~h}$ apart. A leuteolytic dose $(2.0 \mathrm{ml})$ of Prostaglandin $F_{2 \alpha}$ analogue (Prosolvin ${ }^{\circledR}$ Luprostiol 7.5 $\mathrm{mg} / \mathrm{ml}$ ) was also administered to the donor "48 h after" the initiation of superovulation treatment (Maciel, 1991) to the donor. For repeated superovulation treatment with FSH on the same donor there was at least two normal estrous cycles interval for minimizing previous hormone effects according to Hasler (1983). Figure 1 shows the schedule of superovulation using $360 \mathrm{mg}$ of FSH administered in 4 (four) consecutive days at constant dose level.

\section{RESULT AND DISCUSSION}

\section{Ovarian response in different genetic groups treated with FSH}

Mean ovarian response in Local, Pabna and $\mathrm{F} \times \mathrm{L}$ genetic groups in terms of number of corpus luteum (CL), recovered embryo (RE) and of transferable embryos (TE) per donor cow treated with 5 (five) different dose levels of follicle stimulating hormone (FSH) is presented in Figure 2.

The average yield of corpus luteum (CL) was found significantly highest in the $320 \mathrm{mg}$ of FSH dose level and decreased thereafter. The yields of CL were increased gradually from $8.60 \pm 0.60$ to $14.80 \pm 0.66$ indicating a clear impact of FSH dose levels on CL production in Local 


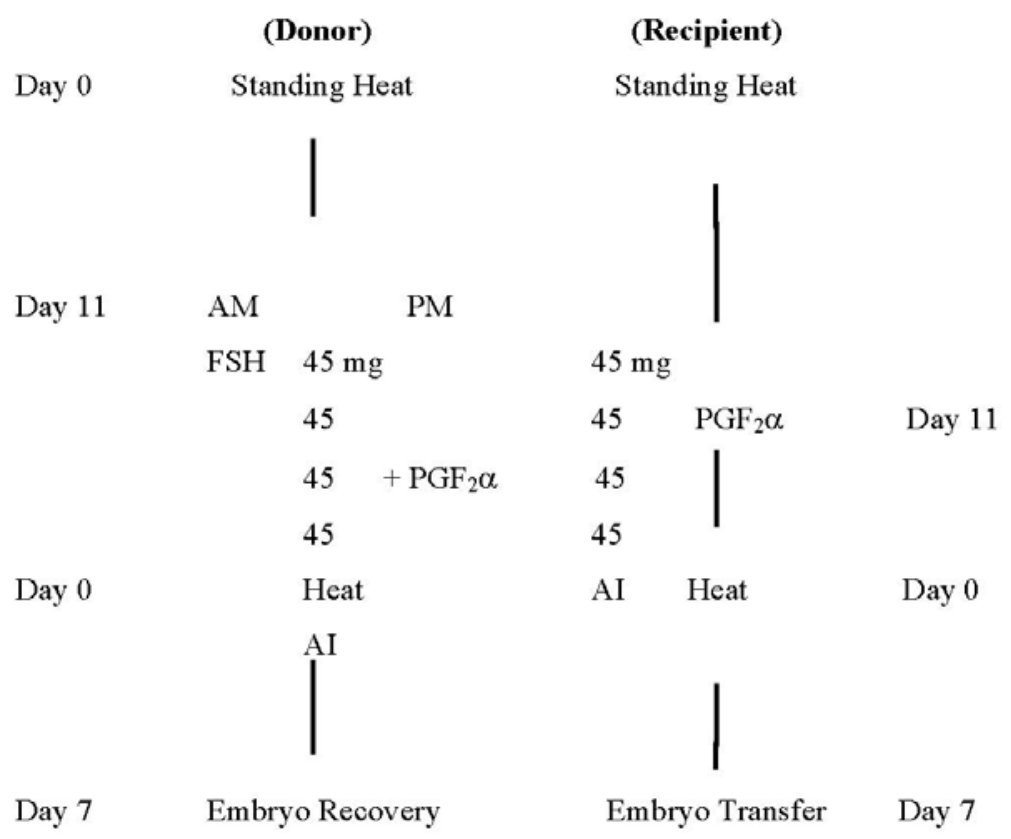

Figure 1. Schedule of superovulation, synchronization and embryo transfer using FSH

genetic group (Table 1). The CL yields in Local genetic group with FSH observed in the present study were in agreement with the findings of Elsden et al. (1978), Chupin and Procureur (1983), Yaakub et al. (1999) and Takedomi et al. (2005), but were higher than those reported by Sugano and Shinogi (1999). The yields of both the recovered embryos (RE) and transferable embryos (TE) showed significantly highest yields in the $280 \mathrm{mg}$ of FSH dose level and thereafter decreased gradually indicating significant impact of $280 \mathrm{mg}$ dose level of FSH on the production of transferable embryos in Local genetic group relating to dose specific response which might be influenced by the genotype and body weight of the experimental donor cows and the day of superovulation induction. The findings of this study suggest that $280 \mathrm{mg}$ of FSH is optimum for superovulation in Local genetic group (Table 1). Findings of RE and TE observed in the present study were in good agreement with those reported by Chupin and Procureur (1983) with different doses of FSH. However, the studies conducted by Sugano and Shinogi (1999), Yaakub et al. (1999) and Neto et al. (2005) who reported relatively lower results, while Gouveia et al. (2002), Andrade et al. (2002)

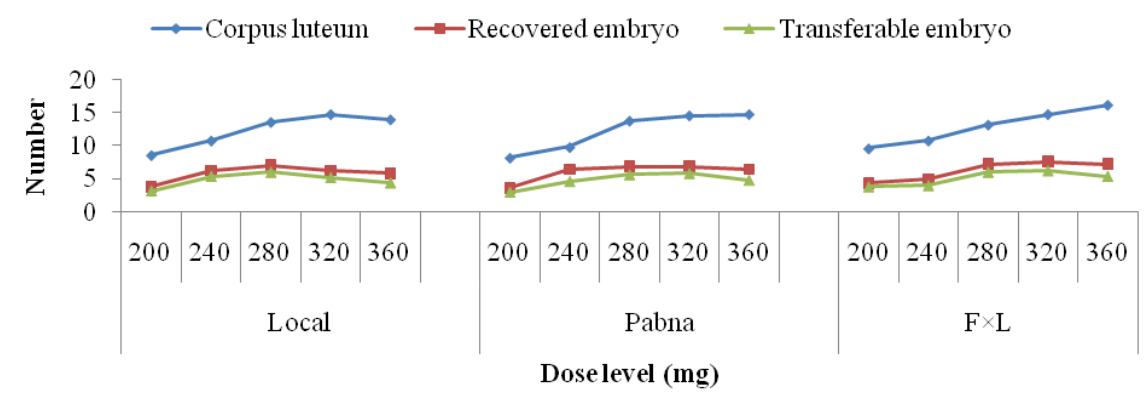

Figure 2. Ovarian response of genetic groups with five different dose levels of FSH

Table 1. Mean number of corpus luteum, recovered embryo and transferable embryo per donor per flush in Local genetic group $(\mathrm{n}=5)$ treated with different doses of FSH

\begin{tabular}{lccccc}
\hline Parameter & \multicolumn{5}{c}{ FSH dose $(\mathrm{mg})$} \\
\cline { 2 - 6 } & 200 & 240 & 280 & \multicolumn{1}{c}{320} & 360 \\
\hline Corpus luteum & $8.60^{\mathrm{a}} \pm 0.60$ & $10.80^{\mathrm{b}} \pm 0.58$ & $13.60^{\mathrm{c}} \pm 0.51$ & $14.80^{\mathrm{c}} \pm 0.66$ & $14.00^{\mathrm{c}} \pm 0.71$ \\
Recovered embryo & $3.80^{\mathrm{a}} \pm 0.37$ & $6.20^{\mathrm{bc}} \pm 0.37$ & $7.00^{\mathrm{c}} \pm 0.32$ & $6.20^{\mathrm{bc}} \pm 0.37$ & $5.80^{\mathrm{b}} \pm 0.37$ \\
Transferable embryo & $3.20^{\mathrm{a}} \pm 0.20$ & $5.40^{\mathrm{bc}} \pm 0.51$ & $6.00^{\mathrm{c}} \pm 0.32$ & $5.20^{\mathrm{bc}} \pm 0.37$ & $4.40^{\mathrm{ab}} \pm 0.68$ \\
\hline
\end{tabular}

Means with uncommon superscripts along the rows differ significantly $(\mathrm{p}<0.01)$. $n=$ Number of donors in each dose level. 
Table 2. Mean number of corpus luteum, recovered embryo and transferable embryo per donor per flush in Pabna genetic group $(\mathrm{n}=5$ ) treated with different doses of FSH

\begin{tabular}{lccccc}
\hline \multirow{2}{*}{ Parameter } & \multicolumn{5}{c}{ FSH dose $(\mathrm{mg})$} \\
\cline { 2 - 6 } & 200 & 240 & 280 & 320 & 360 \\
\hline Corpus luteum & $8.20^{\mathrm{a}} \pm 0.80$ & $9.80^{\mathrm{a}} \pm 0.73$ & $13.80^{\mathrm{b}} \pm 0.37$ & $14.60^{\mathrm{b}} \pm 0.51$ & $14.80^{\mathrm{b}} \pm 0.58$ \\
Recovered embryo & $3.60^{\mathrm{a}} \pm 0.51$ & $6.40^{\mathrm{b}} \pm 0.60$ & $6.80^{\mathrm{b}} \pm 0.49$ & $6.80^{\mathrm{b}} \pm 0.20$ & $6.40^{\mathrm{b}} \pm 0.40$ \\
Transferable embryo & $3.00^{\mathrm{a}} \pm 0.32$ & $4.60^{\mathrm{b}} \pm 0.40$ & $5.60^{\mathrm{b}} \pm 0.68$ & $5.8^{\mathrm{b}} \pm 0.49$ & $4.8^{\mathrm{b}} \pm 0.49$ \\
\hline
\end{tabular}

Means with uncommon superscripts along the rows differ significantly $(\mathrm{p}<0.01) . \mathrm{n}=$ Number of donors in each dose level.

and Barati et al. (2006) found higher number of RE and TE in different studies than those observed in the present study.

The yield of CL in Pabna genetic group showed a linear increasing effect of FSH dose levels and was significantly

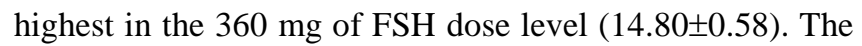
results observed in this study were in agreement to those reported by Elsden et al. (1978), Chupin and Procureur (1983). The yields of RE significantly varied among the FSH dose levels along with similar yield in 280 and $320 \mathrm{mg}$ of FSH levels and then decreased in the $360 \mathrm{mg}$ level indicating the optimum dose effect of FSH in Pabna genetic group in 280 and $320 \mathrm{mg}$ of FSH dose levels. Similarly the yields of TE tended to be a plateau of FSH dose impact leaving the highest TE in $320 \mathrm{mg}$ of FSH dose level. The findings of CL, RE and TE in the study suggests that 280 mg of FSH is optimum for superovulation in Pabna genetic group (Table 2). The findings in Pabna genetic group in this study relating to dose specific response which might also be influenced by the age, genotype and body weight of the experimental donor cows and the day of superovulation induction as in the Local genetic group. The findings of CL, $\mathrm{RE}$ and TE in the present study were found to be close to the findings reported by Chupin and Procureur (1983) with different doses of FSH. However, the observed results in the present study were lower than those reported by Neto et al. (2005) but higher than those reported by Andrade et al. (2002), Gouveia et al. (2002) and Barati et al. (2006) under different situations.

The yields of $\mathrm{CL}$ in $\mathrm{F} \times \mathrm{L}$ genetic group showed an increasing trend of yields with the increase in FSH dose

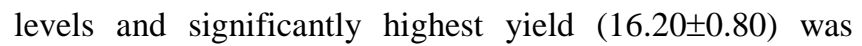
found in the $360 \mathrm{mg}$ level of FSH indicating significant impact of FSH dose levels (Table 3). The findings in this study were little higher than those reported by Kanagawa and Ishikawa (1980) a similar study, but were almost similar to those reported by Chupin and procureur (1983). The yields of RE stood significantly highest in the $320 \mathrm{mg}$ level of FSH and decreased thereafter indicating functional impact of FSH doses in 280, 320 and $360 \mathrm{mg}$ levels. Similarly, the yield of TE was the highest $(6.20 \pm 0.37)$ in the $320 \mathrm{mg}$ level of FSH and decreased thereafter showing functional impact of FSH up to $320 \mathrm{mg}$ of FSH dose level as observed in RE. The observed results in the yields of CL, $\mathrm{RE}$ and TE in the study suggests that $280 \mathrm{mg}$ of FSH is optimum for superovulation in $\mathrm{F} \times \mathrm{L}$ genetic group. The results observed in this study were comparatively lower than those reported by Greve and Lehn-Jensen (1979) and Hasler (1983), but were almost similar to those reported by Darrow (1982). However, the findings were comparatively higher than those reported by Boland et al. (1991), Gouveia et al. (2002), Andrade et al. (2003) and Barati et al. (2006) in various superovulation studies with FSH.

\section{Quality of recovered embryos in different genetic groups treated with FSH}

Mean quality of recovered embryo by rank in Local, Pabna and $\mathrm{F} \times \mathrm{L}$ genetic groups in terms of yield of excellent, good, fair, poor and degenerated embryos per donor cow treated with 5 (five) different dose levels of follicle stimulating hormone (FSH) is shown in Figure 3.

\section{Quality of recovered embryos in Local genetic group}

Findings of the impact of FSH dose levels on the quality (grade) of embryos in different breeds of cattle are scanty in literature. However, the excellent quality embryos in this study showed significant variation in yields in Local genetic group under the impact of different FSH dose levels. The excellent quality embryos showed significantly the highest

Table 3. Mean number of corpus luteum, recovered embryo and transferable embryo per donor per flush in $\mathrm{F} \times \mathrm{L}$ genetic group $(\mathrm{n}=5$ ) treated with different doses of FSH

\begin{tabular}{lccccc}
\hline Parameter & \multicolumn{5}{c}{ FSH dose $(\mathrm{mg})$} \\
\cline { 2 - 6 } & 200 & 240 & 280 & 320 & 360 \\
\hline Corpus luteum & $9.60^{\mathrm{a}} \pm 0.81$ & $10.80^{\mathrm{a}} \pm 0.58$ & $13.20^{\mathrm{b}} \pm 0.37$ & $14.80^{\mathrm{db}} \pm 0.58$ & $16.20^{\mathrm{cd}} \pm 0.80$ \\
Recovered embryo & $4.40^{\mathrm{a}} \pm 0.51$ & $5.00^{\mathrm{a}} \pm 0.32$ & $7.20^{\mathrm{b}} \pm 0.37$ & $7.60^{\mathrm{b}} \pm 0.51$ & $7.20^{\mathrm{b}} \pm 0.37$ \\
Transferable embryo & $3.80^{\mathrm{a}} \pm 0.20$ & $4.00^{\mathrm{a}} \pm 0.32$ & $6.00^{\mathrm{b}} \pm 0.45$ & $6.20^{\mathrm{b}} \pm 0.37$ & $5.40^{\mathrm{b}} \pm 0.40$ \\
\hline
\end{tabular}

Means with uncommon superscripts along the rows differ significantly $(p<0.01) . n=$ Number of donors in each dose level. 


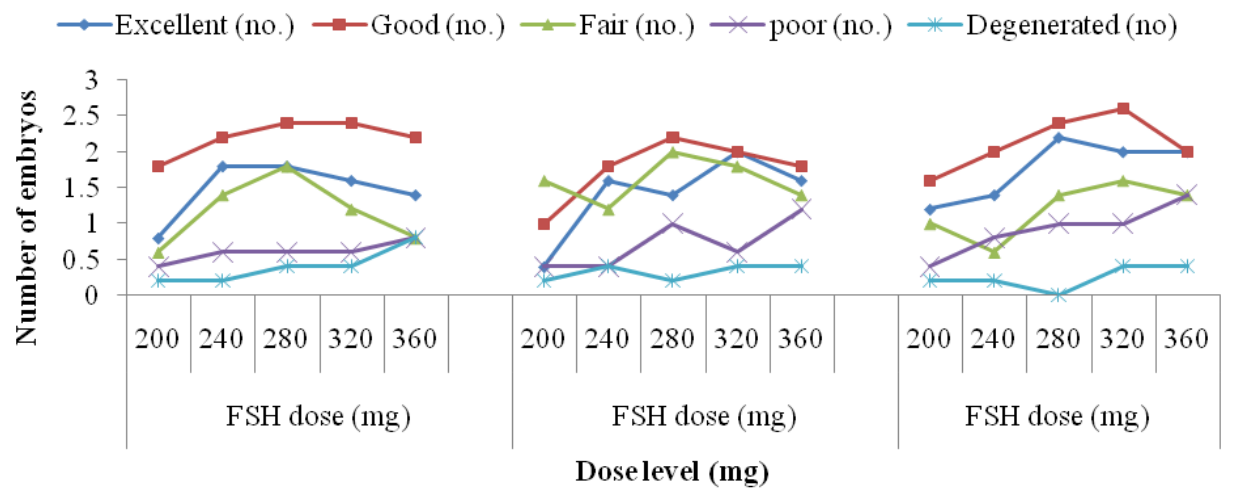

Figure 3. Quality of recovered embryos in genetic groups with five different dose levels of FSH.

yield in the 240 and $280 \mathrm{mg}$ of FSH levels and thereafter decreased gradually (Figure 3 ). There was no significant difference in the yields of good quality embryos, the highest yield was found in the 280 and $320 \mathrm{mg}$ levels of FSH respectively leaving a plateau of FSH dose impact and decreased thereafter. The fair quality embryos showed significantly highest yield $(1.80 \pm 0.20)$ in the $280 \mathrm{mg}$ level and thereafter decreased gradually. On the other hand, both the poor and degenerated quality embryos showed the highest yield in the $360 \mathrm{mg}$ level of FSH. Findings of excellent, good and fair embryos (Table 4) in this study in 240, 280 and $320 \mathrm{mg}$ levels of FSH doses were found to be critically optimum considering the number of transferable embryos which might be attributed to the body weight, physiological status of the experimental donor cows and possibly other factors rather than by the genetic group. Mikkola et al. (2005) reported almost similar results on excellent, good and fair embryo yields to those of Local cattle in the present study, however, the results partially contradicted to those reported by Sugano and Shinogi (1999) Andrade et al. (2003).

\section{Quality of recovered embryos in Pabna genetic group}

The excellent quality embryos showed significantly highest yield (2.00 \pm 0.23$)$ in the $320 \mathrm{mg}$ level indicating significant impact of FSH dose levels on the yield in Pabna genetic group. However, the yields of good, fair, poor and degenerated qualities of embryos were statistically insignificant among themselves, which indicates that the qualities of recovered embryo were independent to FSH dose (Table 5). The observed differences in qualities of embryos with different dose levels might be attributed to variability in ovarian response within and between the donors and type and quality of gonadotrophin used in this

Table 4. Mean quality of recovered embryos per donor per flush in local genetic group $(n=5)$ treated with different doses of FSH

\begin{tabular}{llllll}
\hline Parameter & \multicolumn{5}{c}{ FSH dose (mg) } \\
\cline { 2 - 6 } & \multicolumn{1}{c}{200} & \multicolumn{1}{c}{240} & \multicolumn{1}{c}{280} & 320 \\
\hline Excellent (no) & $0.80^{\mathrm{a}} \pm 0.20$ & $1.80^{\mathrm{b}} \pm 0.20$ & $1.80^{\mathrm{b}} \pm 0.20$ & $1.60^{\mathrm{b}} \pm 0.25$ & $1.40^{\mathrm{ab}} \pm 0.25$ \\
Good (no) & $1.80 \pm 0.20$ & $2.20 \pm 0.37$ & $2.40 \pm 0.40$ & $2.40 \pm 0.40$ & $2.20 \pm 0.37$ \\
Fair (no) & $0.60^{\mathrm{a}} \pm 0.25$ & $1.40^{\mathrm{bc}} \pm 0.25$ & $1.80^{\mathrm{c}} \pm 0.20$ & $1.20^{\mathrm{ac}} \pm 0.20$ & $0.80^{\mathrm{ab}} \pm 0.37$ \\
poor (no) & $0.40 \pm 0.25$ & $0.60 \pm 0.40$ & $0.60 \pm 0.25$ & $0.60 \pm 0.25$ & $0.80 \pm 0.20$ \\
Degenerated (no) & $0.20 \pm 0.20$ & $0.20 \pm 0.20$ & $0.40 \pm 0.25$ & $0.40 \pm 0.25$ & $0.80 \pm 0.20$ \\
\hline
\end{tabular}

Means with uncommon superscripts along the rows differ significantly $(\mathrm{p}<0.05) . \mathrm{n}=$ Number of donors in each dose level.

Table 5. Mean quality of recovered embryos per donor per flush in Pabna genetic group $(n=5)$ treated with different doses of FSH

\begin{tabular}{lccccc}
\hline Parameter & \multicolumn{5}{c}{ FSH dose (mg) } \\
\cline { 2 - 6 } & \multicolumn{1}{c}{200} & $1.60^{\mathrm{b}} \pm 0.24$ & $1.40^{\mathrm{b}} \pm 0.40$ & $2.00^{\mathrm{b}} \pm 0.32$ & $1.60^{\mathrm{b}} \pm 0.40$ \\
\hline Excellent (no) & $0.40^{\mathrm{a}} \pm 0.24$ & $1.80 \pm 0.20$ & $2.20 \pm 0.20$ & $2.00 \pm 0.20$ & $1.80 \pm 0.37$ \\
Good (no) & $1.00 \pm 0.32$ & $1.20 \pm 0.37$ & $2.00 \pm 0.32$ & $1.80 \pm 0.20$ & $1.40 \pm 0.51$ \\
Fair (no) & $1.60 \pm 0.24$ & $0.40 \pm 0.24$ & $1.00 \pm 0.32$ & $0.60 \pm 0.24$ & $1.20 \pm 0.49$ \\
poor (no) & $0.40 \pm 0.24$ & $0.40 \pm 0.24$ & $0.20 \pm 0.20$ & $0.40 \pm 0.24$ & $0.40 \pm 0.24$ \\
Degenerated (no) & $0.20 \pm 0.20$ &
\end{tabular}

Means with uncommon superscripts along the rows differ significantly $(\mathrm{p}<.05) . \mathrm{n}=$ Number of donors in each dose level. 
Table 6. Mean quality of recovered embryos per donor per flush in F×L genetic group $(n=5)$ treated with different doses of FSH

\begin{tabular}{lccccc}
\hline Parameter & \multicolumn{5}{c}{ FSH dose (mg) } \\
\cline { 2 - 6 } & \multicolumn{1}{c}{200} & 240 & 280 & 320 & 360 \\
\hline Excellent (no) & $1.20^{\mathrm{a}} \pm 0.20$ & $1.40^{\mathrm{ab}} \pm 0.24$ & $2.20^{\mathrm{c}} \pm 0.20$ & $2.00^{\mathrm{bc}} \pm 0.00$ & $2.00^{\mathrm{bc}} \pm 0.32$ \\
Good (no) & $1.60 \pm 0.24$ & $2.00 \pm 0.32$ & $2.40 \pm 0.24$ & $2.60 \pm 0.24$ & $2.00 \pm 0.32$ \\
Fair (no) & $1.00 \pm 0.32$ & $0.60 \pm 0.24$ & $1.40 \pm 0.24$ & $1.60 \pm 0.24$ & $1.40 \pm 0.40$ \\
Poor (no) & $0.40 \pm 0.40$ & $0.80 \pm 0.20$ & $1.00 \pm 0.00$ & $1.00 \pm 0.00$ & $1.40 \pm 0.40$ \\
Degenerated (no) & $0.20 \pm 0.20$ & $0.20 \pm 0.20$ & 0.00 & $0.40 \pm 0.24$ & $0.40 \pm 0.24$ \\
\hline
\end{tabular}

Means with uncommon superscripts along the rows differ significantly $(\mathrm{p}<0.05) . \mathrm{n}=$ Number of donors in each dose level

study. Results on embryonic quality in Pabna genetic group suggest that the qualities might be influenced by the individual physiology of the experimental animals and by the gonadotrophin used rather than by the gonadotrophin dose levels and/or the genetic group involved (Figure 3). The findings of this study were almost similar to those reported by Mikkola et al. (2005) on embryo recovery rate and quality in heifers, however, were lower than those reported by Sartori et al. (2003) in an experiment in heifers, lactating and dry cows in summer and winter.

\section{Quality of recovered embryos in $\mathrm{F} \times \mathrm{L}$ genetic group}

The qualities of recovered embryos in $\mathrm{F} \times \mathrm{L}$ genetic group showed almost similar pattern of FSH dose response in yields as were observed in Local and Pabna genetic groups. However, the excellent quality embryos showed significantly highest yield (2.20 \pm 0.20$)$ in $280 \mathrm{mg}$ level of FSH and those of good, fair, poor and degenerated embryos were in the 320, 320, 360 and $320 \mathrm{mg}$ levels of FSH respectively (Table 6). The findings of embryonic quality in the $\mathrm{F} \times \mathrm{L}$ genetic group found in this study showed little or no effect of FSH dose levels, rather the gonadotrophin used and that of the physiological condition of the experimental animals might influence on it (Figure 3). The results in the study were found to be higher than those reported by Mikkola et al. (2005) on excellent, good and fair embryo yields, but were in agreement to those reported by Merton et al. (2003) in a study on quantity and quality of embryos in commercial application of embryo technologies.

Mean number of corpus luteum (CL), embryo recovered (RE) and transferable embryo (TE) were the three parameters for ovarian response in Local, Pabna and $\mathrm{F} \times \mathrm{L}$ genetic groups. In view of optimum yield of TE, it found that all the three genetic groups responded well within 280 to $320 \mathrm{mg}$ of FSH in Local, Pabna and F $\times$ L genetic groups respectively. It might be concluded that the genotype, and body weight of the donor cows used in this study had a functional relationship with FSH dose levels in the yield of $\mathrm{CL}, \mathrm{RE}$ and TE. The findings of CL, RE and TE in this study suggests that $280 \mathrm{mg}$ of $\mathrm{FSH}$ is optimum for superovulation in Local, Pabna and F $\times \mathrm{L}$ cattle genetic groups.
Findings on subjective evaluation of the quality of recovered embryos in Local, Pabna and $\mathrm{F} \times \mathrm{L}$ genetic groups treated with different doses of FSH showed almost little or no impact in yields. It might be concluded that the quality of embryos in Local, Pabna and $\mathrm{F} \times \mathrm{L}$ genetic groups were independent of FSH dose levels, rather it might be attributed to the usual variation in superovulation response within and between the donors, physiological status, age and body weight of individual donor, range of ovulation in superovulation, the lot and batch number of the gonadotrophic hormone used and the day of embryo recovery.

\section{REFERENCES}

Andrade, J. C., M. A. Oliveira, P. F. Lima, A. S. Santos Filho and V. M. Pina. 2002. Use of steroid hormone treatments prior to superovulation in Nelore donors. Anim. Reprod. Sci. 69(1-2): 9-14.

Barati, F., A. Niasari-Naslaji, M. Bolourchi, F. Sarhaddi, K. Razavi, E. Naghzali and W. W. Thatcher. 2006. Superovulatory response of Sistani cattle to three different doses of FSH during winter and summer. Theriogenology 66(5):1149-1155.

Boland, M. P., D. Goulding and J. F. Roche. 1991. Alternative gonadotrophins for superovulation in cattle. Biotechnology programme, University College, Dublin, Faculties of Agriculture and Veterinary Medicine, Belfield, Dublin 4, Ireland. January 1991, Vol. 35, No.1.

Bhuiyan, A. K. F. H., M. M. Hossain and G. K. Deb. 2007. Indigenous cattle genetic resources of Bangladesh and a way forward to their development. Bangladesh J. Prog. Sci. Tech. 5(1):105-112.

Chupin, D. and R. Procureur. 1983. Efficiency of pituitary extracts (FSH) for induction of superovulation in cattle. Anim. Reprod. Sci. 6:11-23.

Darrow, M. D. 1982. Superovulation and fertility in lactating and dry dairy cows. Theriogenology 17:84 (Abstr.).

Directorate of Livestock Services. 2009. Yearly report-2009. Ministry of Fisheries and Livestock. Peoples Republic of Bangladesh.

Elsden, R. P., L. D. Nelson and G. E. Jr. Seidel. 1978. Superovulating cows with follicle stimulating hormone and pregnant mare's serum gonadotrophin. Theriogenology 9:1726.

Faruque, M. O. and A. K. F. H. Bhuiyan. 2001. Cattle and buffalo 
breeding in Bangladesh. Development Strategies for Genetic Evaluation for Beef Production in Developing CountriesProceedings of and International Workshop held in Khon Kaen Province, Thailand, July 23-28, 2001.

Gouveia, M. F., B. J. Nogueira, A. B. Barros, L. A. Teixeira, M. J. Trinca, D’Occhio and C. M. Barros. 2002. Embryo recovery and pregnancy rates after the delay of ovulation and fixed time insemination in superstimulated beef cows. Theriogenology 57(6):1625-1634.

Greve, T. and H. Lehn-Jensen. 1979. Current status of embryotransplantation in Denmark. Theriogenology 11:99 (abstr.).

Hasler, J. F. 1983. Superovulatory responses of Holstein cows. Theriogenology 19:83-99.

Maciel, M. G. 1991. Studies on the ovarian activity of superovulated dairy cattle. M.Sc. thesis, Dept. Of Obstetrics and Gynaecology, Swedish University of Agric. Sci., Uppsala, Sweden.

Merton, J. S., A. P. W. de Roos and E. Mullaart. 2003. Factors affecting oocyte quality and quantity in commercial application of embryo technologies in the cattle breeding industry. Theriogenology 59:651-674.
Mikkola, M., P. Mantysarri, N. Tammiranta, J. Peippo and J. Taponen. 2005. Effect of dietary protein on embryo recovery rate and quality in superovulated heifers. Anim. Reprod. Sci. 87(3-4):193-202.

Neto, A. S., B. V. Sanches, M. Binelli, M. M. Seneda, S. H. Perri and J. F. Garcia. 2005. Improvement in embryo recovery using double uterine flushing. Theriogenology 63(5):1249-1255.

Sartori, R., C. A. Suarez-Fernandez, R. L. Monson, J. N. Guenther, G. J. Rosa and M. C. Wiltbank. 2003. Improvement in recovery of embryos/ova using a shallow uterine horn flushing technique in superovulated Holstein heifers. Theriogenology 60(7):1319-1330.

Sugano, M. and T. Shinogi. 1999. Superovulation induction in Japanese Black cattle by a single intramuscular injection of hMG or FSH dissolved in poyvinylpyrrolidone. Anim. Reprod. Sci. 55(3-4):175-181.

Takedomi, T., H. Kishi, M. S. Medan, Y. Aoyagi, M. Konishi, T. Itoh, S. Yazawa, G. Watanabe and K. Taya. 2005. Active immunization against inhibin improves superovulatory response to exogenous FSH in cattle. J. Reprod. Dev. 51(3):241-2436.

Yaakub, H., D. O'callaghan and M. P. Boland. 1999. Effect of type and quantity of concentrates on superovulation and embryo yield in beef heifers. Theriogenology 51(7):1259-1266. 